\title{
Comparison of Different Asset Pricing Models Based on Alibaba and Tencent Stocks
}

\author{
Simin $\mathrm{Lu}^{1}$, Xiaoyu $\mathrm{Li}^{2}$, Yue $\mathrm{Qi}^{3}$, Zhen Zheng ${ }^{4 *}$ \\ ${ }^{1}$ Research Institution of Economics and Management, Southwestern University of Finance and Economics, Chengdu, \\ Sichuan610000, China \\ ${ }^{2}$ Asia-Australian Business College Liaoning University, Liaoning 110000, China \\ ${ }^{3}$ School of Business Administration, South China University of Technology, Guangzhou, Guangdong 510000, China \\ ${ }^{4}$ School of Finance, Jiangxi University of Finance and Economics, Nanchang, Jiangxi 330000, China \\ *Corresponding author. Email: 2201802856@stu.jxufe.edu.cn
}

\begin{abstract}
Determining the reasonable price for financial assets has always been hot topic in the field. In the search for the factors in the asset pricing, the prevailing methods are Capital Asset Pricing Model (CAPM) and Fama-French factor (FF3F) method. In addition, Dividend Discount Model (DDM) method is also commonly used for stock valuation. The paper deals with evaluating the stock price of Alibaba Group and Tencent using CAPM model, DDM method and FF3F model. Through empirical test, the results obtained by the three models all show that the expected return rate of Tencent Group is greater than that of Alibaba. Through the CAPM model, we consider the impact of market risk on the price of the portfolio, and then we consider the DDM method which focuses on the stock rather than the entire portfolio and simplifies the input and variables compared with the CAPM model. By making a comparison with results of CAPM model and DDM method, we are also comparing the actual value and fair value of the two companies respectively. Finally, FF3F model considers the influence of value premium and size premium based on the CAPM model, and the expected return results obtained are more accurate, which shows that the stock prices of the two companies are overvalued to some extent. In conclusion, the assumptions of CAPM model and DDM method are different, and FF3F model make some improvements based on the CAPM model. In practical application, we should analyze specific problems according to the actual situation.
\end{abstract}

Keywords: Asset valuation, Dividend forecast, Fama-French model, CAPM.

\section{INTRODUCTION}

With the continuous development of the world economy and the increasingly close economic exchanges among countries, the financial market is full of uncertainties, which affect the value of assets in the capital market, cause fluctuations to investors' investment returns. Since the birth of the capital market, economists have never stopped their research and exploration on asset pricing, and have developed various asset pricing models.

For investors, the asset pricing model plays a great role in helping investors to make reasonable valuation of their portfolios and adjust them according to market conditions so as to avoid huge losses caused by unpredictable market fluctuations as far as possible. For the whole capital market, a reasonable valuation of assets can improve the efficiency of the capital market, and some indicators in the model also play a role in macroeconomic forecasting.

One of the oldest and most famous asset pricing models in the financial market is the Dividend Discount Model, also is known as the Gordon Dividend Growth Model [1]. DDM, which is the pioneer of asset quantitative calculation, reflects the relationship between the actual return of stocks and dividend payment. But the model ignores many factors that are important to share prices, such as new products, and market sentiment. After that, Sharp [2] introduced the knowledge of statistics into asset valuation and put forward the Capital Asset Pricing Model CAPM, which concludes that investors obtain high returns by assuming high risks, and is widely used in asset valuation, capital allocation and investment project decision-making in 
the capital market. Based on the CAPM, the FamaFrench 3-factor model [3] had been deeply studied and promoted. It is concluded that the return on assets is related to a series of risk factors such as the market value, and a three-factor model is established to explain the changes in asset prices. There are three stock-market factors: an overall market factor and factors related to firm size and book-to-market equity. To the bond market, there are two factors related to maturity and default risks. Most important, Fama and French [4] concluded that the five factors seem to explain average returns on stocks and bonds.

All three models have ideal assumptions that differ from the real data. As for DDM, Irons [5] believed that the dividend discount model was not suitable for the fast-growing young enterprises with numerous investment opportunities. The debate about the utility of CAPM had been going on ever since it was created.Jagannathan and McGrattan [6] argued about the usefulness and the inadequacy of it and refined the technology to create another version of the model. Based on CAPM, Fama-French 3-factor model was developed to analyze the difference of return rate which cannot be explained by beta value in the CAPM. In addition, some economists, such as Petkova [7] believed that Fama-French 3-factor model not only contributed to asset pricing, but also proposed the predictive role of HML and SMB in excess market returns in his paper.

In this paper, we consider how to evaluate the firm ' $s$ value based on two Chinese companies. We use three traditional asset pricing models the dividend discount model, the capital asset pricing model and the Fama-French 3-factor model to price the stock of Tencent and Alibaba Group, and explore the differences and limitations of the three pricing models through the comparison of the results, so as to help investors better construct and value investment portfolios. Through CAPM, we use the market expected rate of return to calculate the risk-free rate of interest and the expected rate of return of the market portfolio. Thus, the expected rate of return of the two Tencent and Alibaba Group is $12 \%$ and $4.5 \%$. Using DDM, we found that the expected return of Tencent is $10 \%$, and the expected return of Alibaba Group is $8 \%$. Based on the Fama-French 3factor model, we got a different result. The expected rate of return of the two Tencent and Alibaba Group is $6.37 \%$ and $5.54 \%$. Compared to the result of DDM and CAPM, we find that the stock of Alibaba Group is under price, while the stock of Tencent is over price. Through comparison we find that the results of the three calculation methods have certain differences. Investors can use the differences in the calculation results to find arbitrage opportunities.

The reminder of this paper is organized as follow: Section 2 describes the background of the asset pricing problems and the sample we used, Section 3 introduces the three famous model we used to calculate the price of the sample asset and compares the result. The last section presents our conclusion.

\section{EMPIRICAL DATA}

CAPM, DDM and Fama-French 3-factor model are respectively based on certain assumptions, and their calculation results may differ from the real capital market. Therefore, we choose two enterprises in the capital market: Tencent and Alibaba Group, and use the public data in the stock market for calculation.

The sample period started from March 1, 2019 and ends on March 2, 2020, with 248 trading days of data of each company. We finally get the expected return and the standard deviation during 248 trading days from March 1, 2019 to March 2, 2020 (as can be seen in Table 1). We chose Hang Seng Index as the market portfolio(M). Through calculation, we found that the standard deviation of the market portfolio is equal to 0.5 , and the correlation with itself is equal to 1 .

And Table 1 shows the market expected return, standard deviation, correlation, current price and dividend and the growth rate of dividend about the stock of Alibaba Group and Tencent. As we can see from Table 1, the expected return of Tencent and Alibaba Group is equal to $7.2 \%$ and $8.4 \%$, while through calculation the standard deviation is equal to 0.4 and 0.3 . By inquiring the company's dividend issue policy, we select the company's current dividend and dividend growth rate, as shown in Table 1 . The dividend growth rate of Tencent is $0 \%$, while that of Alibaba Group is equal to $2 \%$.

Table 1. Detailed information about the stock of Alibaba and Tencent.

\begin{tabular}{lll}
\hline & Tencent & Alibaba Group \\
\hline Expected Return & $7.2 \%$ & $8.4 \%$ \\
Standard Deviation & 0.4 & 0.3 \\
Correlation with $\mathrm{M}$ & 0.3 & 0.8 \\
Current Price $\left(\mathrm{P}_{0}\right)$ & 100 & 127.5 \\
Current Dividend $\left(\mathrm{D}_{0}\right)$ & 8 & 10 \\
Dividend growth rate $(\mathrm{g})$ & $0 \%$ & $2 \%$ \\
\hline
\end{tabular}

Using the above data, we respectively use three models to measure stock prices and compare the results, so as to provide investors with different pricing methods and construct an optimal investment portfolio.

\section{METHOD}

Our paper aims to compare the valuation results of different pricing models, CAPM, DDM and FamaFrench Three Factor Model. In this part, we introduce 
these three pricing methods in order, including their background and theories and we choose two companies to calculate expected return using different methods as the empirical part.

\subsection{Capital Asset Pricing Model}

\subsubsection{Background and theory}

CAPM is an extension of Mean-variance analysis. When we change the weights of portfolios, we can calculate the expected return and standard deviation of different portfolios, but we want to form an optimal portfolio. Due to the mean-variance analysis, Markovitz [8] first put forward the mean variance model, which has assumptions that the investors only focus on the expected return and volatility. Besides, investors are risk averse, which means that at a given return level, investors will choose low-risk assets to invest, conversely, at a certain risk level, investors will choose highest-return asset to invest.

After that, Tobin [9] proposed the Two-fund separation theorem based on Markwitz's theory. According to the theorem, different points on the effective frontier represent different asset portfolios, and any other asset portfolios represented by one point can be composed of the assets represented by two points. Combined with the above theories, it can be proved that any asset portfolio (except the completely positive correlation) can reduce the risk level through certain combination. Therefore, investors can use Markovitz's portfolio variance formula to calculate the portfolio ratio of various assets at a certain return level to reduce the total risk of investment.

Sharpe [2] put forward the capital asset pricing model (CAPM), which takes the risk-free asset into consideration, confirmed that investment portfolio represented by each point on capital market line can be formed by the junction of risky assets and risk-free asset. From the figure we can see that in a situation that there is a risk-free asset, the line from risk-free asset points that tangent to the efficient frontier has the highest expected return for a given standard deviation. This line is called the Capital Market line. All portfolios on this line involve two investments: one in the tangency portfolio $\mathrm{T}$ and one in the risk-free asset, and in this case, the point $\mathrm{T}$ refers to the market portfolio. While different individuals have their own indifference curve, so the optimal portfolio for an individual investor is the point of tangency between Capital market line and investors' indifference curve.

However, CML doesn't indicate the relationship between the risk of single risky security or the nonefficient security portfolio and its return. Markovitz points that the risk of any security can be divided into systematic risk and unsystematic risk. The unsystematic risk is the risk that can be eliminated by holding welldiversified portfolios, while the systematic risk can' $t$ be reduced by diversification. To measure systematic risk, we introduce Beta. Beta represents the sensitivity of an asset' s return to the market return. The following formula indicates that the larger the absolute value of Beta, the larger the security risk and its sensitivity to the market portfolio.

$\beta_{\mathrm{i}}=\frac{\operatorname{Cov}\left(\mathrm{R}_{\mathrm{i}}, \mathrm{R}_{\mathrm{M}}\right)}{\sigma_{\mathrm{M}}^{2}}$

Later, after the improvement and modification by Lintner [10] and Myosin [11], the current general capital asset pricing model was formed, which was used to guide investment decisions. It assumes that the market allows individual investors lend and borrow at risk-free rate, and there is no tax and transaction cost. This model indicates the relationship between security return and risk in the equilibrium market, namely the security equilibrium price. Here is the formula of CAPM:

$\left.E\left(R_{i}\right)=R_{f}+\beta_{i}\left[E\left(R_{M}\right)-R_{f}\right)\right]$

To sum up, the capital asset pricing model elaborates the correlation between asset rate of return and risk in the equilibrium market. Investors can measure whether the assets on the market price is reasonable based on the equilibrium pricing benchmark, CAPM can also be used as a method of pricing guidance to price the listed companies and to predict the effects of all kinds of changes in market factors on asset prices. Therefore, we choose this pricing methods to see whether its valuation results are accurate.

\subsubsection{Empirical analysis}

Given the characteristics of stocks in Alibaba and Tencent, we can calculate the $\beta$ of them:

We used $\beta=\frac{\operatorname{Cov}\left(R_{a}, R_{M}\right)}{{ }^{\sigma}}$ to calculate their Beta, and obtained $\beta_{\mathrm{a}}=0.24, \beta_{\mathrm{t}}=0.48$

Given that the Alibaba has expected return of $7.2 \%$ and Tencent has expected return of $8.4 \%$, we used $\left.E\left(R_{i}\right)=R_{f}+\beta_{i}\left[E\left(R_{M}\right)-R_{f}\right)\right]$ to calculate the Riskfree rate and the market expected return respectively. Getting the result of $E\left(R_{M}\right)-R_{f}=5 \%, R f=6 \%$ and $\mathrm{R}_{\mathrm{M}}=11 \%$.

Then we can calculate the expected return in Alibaba and Tencent using CAPM by $E\left(R_{i}\right)=R_{f}+$ $\left.\beta_{i}\left[E\left(R_{M}\right)-R_{f}\right)\right]$, we obtained $E\left(R_{A}\right)=4.5 \%$, $\mathrm{E}\left(\mathrm{R}_{\mathrm{T}}\right)=12 \%$. 


\subsection{Dividend Discount Model (DDM)}

\subsubsection{Background and theories}

One of the oldest and most trusted models in financial theory is the Dividend Discount Model (DDM), also known as the Gordon Model [1]. It values stocks as the present value of expected future dividends based on two simple inputs: the expected dividend payout in time $n, D_{n}=E_{0}\left(D_{n}\right)$ and the discount rate of stockholders, i.e., cost of equity capital (assume a flat term structure $r_{t}=r$ ). The formula of dividend discount model is:

$P_{0}=\frac{D_{1}}{(1+r)^{1}}+\frac{D_{2}}{(1+r)^{2}}+\cdots+\frac{D_{n}}{(1+r)^{n}}=\sum_{n=1}^{\infty} \frac{D_{n}}{(1+r)^{n}}$

According to Bodie et.al, what the model tells us is that the price at which you can sell a stock in the future depends on dividend forecasts at that time [12].

However, the formula (3) stands is still not very useful in valuing a stock because it requires dividend forecasts for every year into the indefinite future. In that case, to make the DDM practical, some simplifying assumptions are needed to introduce. Therefore, we assume that dividends are trending upward at a stable growth rate that we will call g. (e.g., $\mathrm{D}_{1}=\mathrm{D}_{0} \times$ $\left.(1+\mathrm{g}) ; \mathrm{D}_{2}=\mathrm{D}_{0} \times(1+\mathrm{g})^{2} ; \mathrm{D}_{3}=\mathrm{D}_{0} \times(1+\mathrm{g})^{3}\right)$

Using these dividend forecasts in formul (3), we can solve the stock price as:

$P_{0}=\frac{D_{0}(1+g)}{1+r}+\frac{D_{0}(1+g)^{2}}{(1+r)^{2}}+\frac{D_{0}(1+g)^{3}}{(1+r)^{3}}+\cdots+\frac{D_{0}(1+g)^{n}}{(1+r)^{n}}$

This equation can be simplified to:

$P_{0}=\frac{D_{0}(1+g)}{r-g}=\frac{D_{1}}{r-g}$

The equation (5) is called the constant-growth DDM, or the Gordon model, after Myron J. Gordon, who popularized the model. It is a generalization of the perpetuity formula to cover the case of a growing perpetuity. As $g$ increases (for a given value of $D_{1}$ ), the stock price also rises. However, a firm in a "steady state" cannot have a growth rate that exceeds the growth rate of the economy in which the firm operates according to Charumathi and Suraj [13].

\subsubsection{Advantage and disadvantage}

After introducing the background and theories of the DDM, here illustrate its advantages and disadvantages.

As for its advantages, it is seen as the simplest model for valuing the securities price, and it is considered as a fundamental approach to value securities price. In other words, the development of some other price-valued advanced models is based on the DDM. Furthermore, it will not be influenced by current share market circumstances.

When it comes to disadvantages, initially, the assumption of this model is unrealistic. The interest rate and expected future dividends all the time. It is unrealistic to forecast future dividends. Therefore, the price of the stocks it assesses will not exactly consist with the actual price. Furthermore, the DDM is more suitable for the company with an established history since it has stable dividend payments. In that case, the expected future dividends can be forecasted closer to the actual figure. However, it is relatively not that suitable for the new company or the company that does not pay constant dividends or even does not pay dividends at all. In that case, the dividends cannot be forecasted suitable and the price it assesses will not be exactly suitable. Finally, the constant-growth DDM assumes the $g$ is lower than $r$; however, it is kind of invalid. Since the investors are consist of various kinds of people, their emotionsfluctuated constantly. There are some environmental factors that influence their decisions and affect the return on earnings. The DDM does have great influences on the price evaluation; however, it is limited by various factors.

\subsubsection{Empirical analysis}

In this part, we will apply the DDM to value the stock price in Alibaba Group and Tencent using their current dividends and expected future dividends. According to the figures illustrated in part 2, We used $\mathrm{r}=\frac{\mathrm{D}_{1}}{\mathrm{P}_{0}}+\mathrm{g}$ to calculate its expected return and obtain the expected return in Alibaba Group is $r_{A}=8 \%$, and we used $r=\frac{D_{1}}{P_{0}}+g$ to calculate its expected return andobtain $\mathrm{r}_{\mathrm{T}}=10 \%$.

According to the results above, we can find that compared to the results under CAPM, the expected return under DDM in Alibaba Group is higher, which means the value of stocks in Alibaba Group is underpriced; while the expected return under DDM in Tencent is lower, which illustrates that the value of stocks in Tencent is overpriced.

\subsection{Fama and French Three Factor Model (FF3F)}

\subsubsection{Background and theories}

Although CAPM theory has won the Nobel Prize, there are still a series of empirical research results, which put forward a series of questions of CAPM. Tinic et al [14] examined the seasonality in the basic relationship between expected return and risk during $1935-82$, the results revealed that the risk premiums during the eleven months were not significantly different from zero. Since the CAPM theory is based on 
efficient market hypothesis, it is difficult to leave out the controversy over the hypothesis given the manifestations of price anomalies [15]. Ball [16] pointed earnings variables proxy for omitted variables or other misspecification effects in the two-parameter model. Furthermore, Banz [17] proved the size effect has been in existence for at least forty years in NYSE, drawing attention to the negative relationship between return on equity and the firms' equity value. In addition, Basu [18] confirmed that the common stock of high E/P firms earned higher risk-adjusted returns than the common stock of low E/P firms on average. Thus, Fama et al [19] studied the explanatory power of listed company size (ME) and book to market ratio (BE/ME) on stock price changes and stock returns, they that the explanatory power of listed company size and book to market ratio on stock returns was better which cannot be described by CAPM. Therefore, Fama and French formally put forward the Fama-French three-factor model (FF3F). They expanded the CAPM by adding size risk and value risk factors to the market risk factor in CAPM.

\subsubsection{Formula and Test}

The formula for the FF3F model is:

$\mathrm{R}_{\mathrm{it}}-\mathrm{R}_{\mathrm{ft}}=\alpha_{\mathrm{it}}+\beta_{1}\left(\mathrm{R}_{\mathrm{Mt}}-\mathrm{R}_{\mathrm{ft}}\right)+\beta_{2} \mathrm{SMB}_{\mathrm{t}}+\beta_{3} \mathrm{HML}_{\mathrm{t}}$

where $R_{M t}-R_{f t}$ represents the excess return on the market portfolio, $\mathrm{SMB}_{\mathrm{t}}$ represents the size premium and $\mathrm{HML}_{\mathrm{t}}$ represents the value premium. Fama and French proved that $\mathrm{ME}$ and $\mathrm{BE} / \mathrm{ME}$ are risk factors of stock returns. This study provides necessary theoretical support for the three-factor model. To verify the practicability of the model, Fama and French tested various effects, such as short-term return inertia effect, book to market ratio effect, and return growth rate effect etc.

In the aspect of empirical test, the study conducted by Connor and Sehgal [20] empirically examined the FF3F model of stock returns in India. The share price data consisted of month-end adjusted share prices of 364 companies from June 1989 to March 1999. They found that cross-sectional mean returns were explained by exposures to these three factors, and not by the market factor alone. The empirical results are reasonably consistent with the FF3F model.

\subsubsection{Empirical Test}

In this part, we compare the return of two companies using the FF3F model. The coefficients of the three factors are selected from Kenneth R. French's database, which is the data obtained by French according to the relevant information of the US stock market. The data of three factors are obtained by Shenzhen Xishima Data Technology Co., Ltd. on the stock market data statistics in December 2020. These data are included in Table 2 and Table 3.

Based on Table 2, using Kenneth R. French's database information, the $\beta$ values of the excess return on market portfolio (Mkt), size premium (SMB) and value premium (HML) are 2.79, 2.11 and 7.07 respectively.

Table 2. Coefficients of FF3F model:

\begin{tabular}{clll}
\hline & Mkt & SMB & HML \\
\hline Coefficients & 2.79 & 2.11 & 7.07 \\
\hline Source: Selected from &
\end{tabular}

Source: Selected from Kenneth R. French's database

As we can see from Table 3, Shenzhen Xishima Data Technology Co., Ltd. calculated the values of excess return on market portfolio (Mkt), size premium (SMB) and value premium (HML) for Alibaba and Tencent stock respectively. For two companies, the values of excess return on market portfolio (Mkt) are 0.055 and 0.016. The values for the size premium (SMB) are -0.125 and -0.039 . Moreover, the values for the value premium (HML) are -0.05 and 0.058 .

Table 3. The value of three factors of FF3F model

\begin{tabular}{lll}
\hline Company & Alibaba & Tencent \\
\hline Mkt & 0.055 & 0.016 \\
SMB & -0.125 & -0.039 \\
HML & -0.05 & 0.058 \\
\hline
\end{tabular}

Source: Calculated by Shenzhen Xishima Data Technology Co., Ltd.

Then by adding the above information into $R_{i t}=$ $\alpha_{i t}+\beta_{1}\left(R_{M t}-R_{f t}\right)+\beta_{2} S_{M B}+\beta_{3} H_{M L}+R_{f t}$, we can roughly calculate the expected return in Alibaba Group according to Equation 6 and obtain $\mathrm{R}_{\mathrm{A}}=5.54 \%$. Then, the expected return in Tencent is calculated as $\mathrm{R}_{\mathrm{T}}=6.37 \%$

The result of the FF3F model shows the same trend as the above two methods. By adding the influence of size premium and value premium, the result is more accurate compared to the CAPM method. The result of the FF3F model also shows that the expected return of Alibaba company $(5.54 \%)$ is lower than the expected return of Tencent company (6.37\%). However, comparing to the information of the stock of two companies, the result under the FF3F model indicates that the expected return of two companies may overestimated $(7.2 \%$ and $8.4 \%$ compared with $5.54 \%$ and $6.37 \%$ respectively). This maybe the result of considering the influence of size premium and value premium.

\section{CONCLUSION}

In this paper, we reviewed three asset pricing theories, namely Capital Asset Pricing Model, Dividend Discount Model and Fama-French 3-factor model, to help investors make reasonable valuation of assets and 
construct optimal investment portfolios according to their risk preference types and capital market risk conditions. Meanwhile, we take Alibaba Group and Tencent as examples to illustrates three theories respectively based on empirical data to combine the theories we illustrate above with practical analysis.

Generally, in the parts above, we calculate the expected return of Alibaba Group and Tencent using three assets pricing model. Under CAPM, the expected return is $4.5 \%$ in Alibaba Group and $12 \%$ in Tencent; under DDM, the expected return in two companies is $8 \%$ and $10 \%$. It is widely acknowledged that the results from the CAPM are regarded as fair value, and the results from the DDM are regarded as actual value. As the results illustrate in Alibaba Group the actual value is larger than fair value, which represents the stock in Alibaba Group is underpriced; while, in Tencent the actual value is less than actual value, which represents the stock in Tencent is overpriced. In that case, arbitrage opportunities will exist, investors can achieve capital gain by selling the stocks that are overpriced and buying the stocks that are underpriced. Therefore, investors can make profits due to the arbitrage opportunities.

As for FF3F model, it shows the same trend as the other two models; however, based on the database the results under this model are more accurate. Under FF3F model, the expected return is $5.54 \%$ and $6.37 \%$ respectively in Alibaba Group and Tencent. However, compared to the actual dividend return $8.4 \%$ and $7.2 \%$, both of these stocks are overpriced. To sum up, according to the analysis above, we consider the stocks in Tencent worth the investment.

However, our analysis also has some limitation. Initially, for dividend discount model, the dividend paid in different companies is irregular. In some new companies or some companies which do not make a profit in the current year, they may pay just a little sum of dividends or even do not pay dividends at all. It is widely acknowledged that the economic fluctuates all the time. In that case, it is different to forecast the expected future dividend correctly and reasonably. In our paper, we find that these three models are all efficient in stock valuation in the large-scale companies which are in the electronic information technology fields. In the further study, we will expand our study to the company in other fields and the company in the different scales to examine how these three valuation models work.

\section{REFERENCES}

[1] Gordon, M. J. (1962). The investment, financing, and valuation of the corporation. Homewood, IL: RD Irwin.
[2] Prices, C. A. (1964). A theory of Market Equilibrium under Conditions of Risk. Journal of Finance, 19(3), 425-444.

[3] Fama, E. F., \& French, K. R. (1992). The crosssection of expected stock returns, Journal of Finance. Journal of Finance, 47(2), 427-465.

[4] Fama, E. F., \& French, K. R. (2021). Common risk factors in the returns on stocks and bonds (pp. 392449). University of Chicago Press.

[5] Irons, R. (2014). Enhancing the dividend discount model to account for accelerated share price growth. Journal of Accounting and Finance, 14(4), 153.

[6] Jagannathan, R., \& McGrattan, E. R. (1995). The CAPM debate. Federal Reserve Bank of Minneapolis Quarterly Review, 19(4), 2-17.

[7] Petkova, R. (2006). Do the Fama-French factors proxy for innovations in predictive variables?. The Journal of Finance, 61(2), 581-612.

[8] Markowitz, H. M. (1968). Portfolio selection. Yale university press.

[9] Tobin, J. (1958). Liquidity preference as behavior towards risk. The review of economic studies, 25(2), 65-86.

[10] Lintner, J. (1975). The valuation of risk assets and the selection of risky investments in stock portfolios and capital budgets. In Stochastic optimization models in finance (pp. 131-155). Academic Press.

[11] Mossin, J. (1966). Equilibrium in a capital asset market. Econometrica: Journal of the econometric society, 768-783.

[12] Bodie, Z., Kane, A., \& Marcus, A. J. (2013). Investments and portfolio management. McGraw Hill Education (India) Private Limited.

[13] Charumathi, B., \& Suraj, E. S. (2014). THE RELIABILITY OF DIVIDEND DISCOUNT MODEL IN VALUATION OF BANK STOCKS AT THE BOMBAY STOCK EXCHANGE. CLEAR International Journal of Research in Commerce \& Management, 5(3)

[14] Tinic, S. M., \& West, R. R. (1984). Risk and return: Janaury vs. the rest of the year. Journal of Financial Economics, 13(4), 561-574.

[15] Paliienko, O., Naumenkova, S., \& Mishchenko, S. (2020). An empirical investigation of the FamaFrench five-factor model. Investment Management \& Financial Innovations, 17(1), 143. 
[16] Ball, R. (1978). Anomalies in relationships between securities' yields and yield-surrogates. Journal of financial economics, 6(2-3), 103-126.

[17] Banz, R. W. (1981). The relationship between return and market value of common stocks. Journal of financial economics, 9(1), 3-18.
[18] Basu, S. (1983). The relationship between earnings' yield, market value and return for NYSE common stocks: Further evidence. Journal of financial economics, 12(1), 129-156. 